\title{
The Effect of Audiovisual Education on Physical Activity Tendencies in Secondary School Children
}

\author{
Abdullah Güllü̈ \& Esin Güllü \\ ${ }^{1}$ Faculty of Sport Sciences, Hitit University, Çorum, Turkey \\ Correspondence: Abdullah Güllü, Faculty of Sport Sciences, Hitit University, Çorum, Turkey.
}

Received: December 3, 2018

Accepted: January 5, 2019

Online Published: February 26, 2019

doi:10.5539/ies.v12n3p81

URL: https://doi.org/10.5539/ies.v12n3p81

\begin{abstract}
The aim of this study was to investigate the effect of audiovisual education method on the physical activity tendencies of 13-year-old secondary school students. A total of 66 healthy and voluntary male students who were aged 13 years in secondary school participated in this study. The participants were randomly divided into three groups: an educational group (EG; $\mathrm{n}: 22$; height: $146.51 \pm 9.01 \mathrm{~cm}$; weight: $37.73 \pm 12.20 \mathrm{~kg}$ ), educational group with parents (EGP; n: 23; height: $146.97 \pm 7.19 \mathrm{~cm}$; weight: $42.04 \pm 11.39 \mathrm{~kg}$ ) and a control group (CG; $\mathrm{n}: 21$; height: $141.53 \pm 8.27 \mathrm{~cm}$; weight: $39.62 \pm 11.72 \mathrm{~kg}$ ). EG and EGP completed their audiovisual education program in 2 days of the intervention week. Total energy expenditure (TEE), physical activity level (MET), STEP, physical activity duration, lying-down duration and sleep duration values were taken with SenseWear Armband in 6 consecutive days during 24 hours. These values of the study group were taken before (pre-test) and after (post-test) the intervention week. The variances between the groups were determined by one-way ANOVA, and multiple comparisons were used to determine possible differences. The level of significance was used at 0.05 . After the audiovisual education programs, a significant increase were observed in the TEE, STEP and MET values of the groups. According to the CG, the TEE and MET values were significantly higher in favor of EGP, and in STEP was also significantly higher in favor of EG and EGP. The audiovisual education programs may contribute to increase physical activity levels by affecting the children's intrinsic motivations. Also, the family played an effective role in physical activity trends, and therefore, increased the inner motivation of the child, and caused the negative behaviors to be positively changed.
\end{abstract}

Keywords: audiovisual education, physical activity, SenseWear armband, secondary school education

\section{Introduction}

Physical activity is defined as activity that involves energy consumption using our muscles and joints in our daily life, increases heart and respiratory rate, can be performed at different intensities and result in fatigue (Thompson, Gordon, \& Pescatello, 2009; Der Ananian \& Prohaska, 2007) and physical activity is shown to be the most important factor in the fight against obesity, diabetes, cancer, hypertension, osteoarthritis, osteoporosis and cardio-vascular diseases, Alzheimer's disease and other forms of dementia (World Health Organization [WHO], 2015; Donnelly et al., 2009).The contribution of physical activity is not limited to this, but it plays an active role in the fight against depression and anxiety (Aylaz, Gullu, \& Gunes, 2011). It is stated that it improves the self-confidence and also affects the psycho-social development positively. Childhood is the first stage for the prevention of chronic diseases due to the fact that the foundations of diseases are laid first (Republic of Turkey Ministry of Health, Public Health Agency of Turkey [RTMH], 2014).

\subsection{Research Problem}

Nowadays, unfortunately, advancing technology has entered human life with a great speed and has made people of all ages dependent on themselves. These rapid developments in business life, urbanization, population growth, ease of transportation and a more comfortable lifestyle limit human activities and lead to a more physical inactive life. However, this situation affects public health negatively and causes serious health problems. Hence, the orientation of our children to physical activity is of great importance for public health, and especially for the formation of healthy generations in the future.

Turkey Nutrition and Health Survey indicated that $58.4 \%$ of our $6-11$ age group children are not regularly (30 minutes or more times daily) exercising. When the age groups are examined in detail, the rate of men who do not 
exercise at all is reported to be $41.4 \%$ in the $12-14$ age group and $44.6 \%$ in the $15-18$ age group. Thus, the average 6-hour period is spent inactive for TV, computer, internet, homework, course work in these age groups (RTMH, 2014). In addition, according to WHO's data (2015), physical inactivity (lack of physical activity) has been identified the fourth important risk factor among global causes of death. Furthermore, physical inactivity is estimated to be the main cause of $9 \%$ of breast and $10 \%$ colon cancers, $7 \%$ of diabetes and $5 \%$ of coronary heart disease, and account for $10 \%$ of deaths worldwide. Changing life styles also negatively affect our children. Many studies in which different methodological approaches and evaluations have been taken into account emphasized that decrease the physical activity levels and motor skills performance of children and adolescents (Graf et al., 2014) and at the same time increase in obesity and type-2 diabetes (RTMH, 2014). Also, children between the ages of 10-19 constitute 20\% of the world population (The State of World Population [SWP], 2014). In Turkey, the share of this age group in the total population shows similarities with the distribution in the world (Turkey Statistical Institute [TSI], 2010). In this period, the developmental age is characterized by physical and psychological changes, and includes a period of second rapid development after infancy. $15 \%$ of adulthood and $50 \%$ of body weight is gained during this period (Cordeiro, Lamstein, Mahmud, \& Levinson, 2005), and also the foundations of diseases are discarded in this period (RTMH, 2014).

With the developing technologies of the 21 st century, reading in the traditional sense is losing power day by day in the face of listening and watching (Lester, 2000). When it is thought that images in the mind are processed at 60.000 times faster than words, nowadays, it is no wonder that there are discussions about what is being watched more than read among the students. This change in the student profile makes it necessary for educators to organize their educational environment in a way that addresses the world of students. Briefly, visual teaching materials are pictured the verbal information that helps the mental activities of the learning process. The sense of sight, which has the most effect on learning, is around $83 \%$ in the ratio of what we have learned. The ratio of what we learned with our other senses is as follows: hearing $11 \%$, sniffing $3.5 \%$, touch $1.5 \%$, tasting $1 \%$ (Büyükkaragöz \& Civi, 1998). Some of the simplest ways to address the sense of vision are the preparation of different images, presentation and demonstration. Such materials like graphs, photographs, concept maps, slides, films and computers can be shown as examples. Visual teaching materials help the student to promote his/her orientation, gather attention, analyze and synthesize. A well-designed schematic representation provides more insight and ease of remembering than the meanings of words (Gentry, 1994). Although national health guidelines have advocated increased physical activity in children and adolescents, certain goals have still not been achieved (Myles, Mary, Tim, Moonseong, \& Angelo, 2002). Among the reasons that cause a lack of motivation for a physically more active life, the awareness of children and families about physical activity has been shown to be low (RTMH, 2014). In addition, it is reported that more data are needed for variables that affect children's decision to be active or sedentary (Myles et al., 2002).

\subsection{Hypothesis}

In this study, a program was prepared based on the information from the Physical Activity Guideline published by the Ministry of Health (RTMH, 2014). This program was prepared by taking into consideration the general principles of teaching methods, and included the addition of audiovisual training materials with the weight of a visual video, picture, film and slide. This audiovisual educational program was applied to secondary school students and to the secondary school students with their parents, at the weekend. Accordingly, we investigated some relevant theories in order to find out the possible effects of audiovisual educational programs on the intervention group. These relevant theories were: (1) the audiovisual education programs may contribute to increase physical activity levels by affecting the children's intrinsic motivations, and (2) the parents may play an effective role on their child's in physical activity tendencies, and therefore, (3) they may increase the inner motivation of their child, and may cause the negative behaviors to be positively changed.

\subsection{Purpose of the Study}

The purpose of this study was to examine the possible effects of the audiovisual educational methods applied during the intervention week on physical activity tendency levels of (1) the educational group, and (2) the educational group participated together with their parents.

\section{Methods}

\subsection{Subjects}

66 healthy and voluntary male students, aged 13 years, were selected from the 7th grade of state schools affiliated to the Ministry of National Education. A total of 66 participants were randomly divided into three groups: an educational group (EG; n: 22 ; height: $146.51 \pm 9.01 \mathrm{~cm}$; weight: $37.73 \pm 12.20 \mathrm{~kg}$ ), an educational group with parents (EGP; n: 23; height: $146.97 \pm 7.19 \mathrm{~cm}$; weight: $42.04 \pm 11.39 \mathrm{~kg}$ ) and a control group (CG; n: 
21; height: $141.53 \pm 8.27 \mathrm{~cm}$; weight: $39.62 \pm 11.72 \mathrm{~kg}$ ) that did not participate in any educational program. Some criteria were taken into consideration in the selection of the children in the research group: be allowed by their families, no physical activity or being in any sports branch on a regular basis except for physical education classes, non-smoking, no chronic disease, and no regular any medication use.

\subsection{Permission Operations}

Before starting work, necessary permits were obtained from Provincial Directorate of National Education and school administration. Subsequently, "the student/parent information form" and "the student/parent consent form" which were prepared according to the rules in the Helsinki Declaration, were sent to each participant. Parents were also asked to complete a medical health history questionnaire and to give verbal consent to the research staff in order to determine whether they were suitable for the study. Parents gave written and signed consent, after reviewing all forms.

\subsection{Study Process}

For the study, a team was constituted which composed of a pedagogue, a psychological counseling and guidance specialist, a training program development specialist and a physical education teacher. This team prepared an educational program with the addition of audiovisual instructional materials with a visual weight of videos, pictures, films and slides. This program was based on the information from Turkey's Physical Activity Guideline issued by the Ministry of Health, which included the health benefits of physical activity, damages of inactivity and how to be more active in the day (RTMH, 2014).

The visuals were prepared by taking into consideration the general principles of teaching methods (e.g. relative to the child, from known to unknown, from closely to away, from concrete to abstract, clearance, linking with life, etc.). This prepared program was constituted from 4 different course periods, each of which is 40 minutes. This educational program was administered as a total of 4 sessions on 2 days of the week (first day: $40 \mathrm{~min} .+40$ min., and second day: $40 \mathrm{~min}$. $+40 \mathrm{~min}$.). It was presented to the EG, and to the EGP on weekend in different 2 days by the same expert instructors using visual and auditory teaching materials. For CG, no educational program was implemented.

\subsection{Pre-experimental Tests}

The anthropometric measurements of the students were taken as shorts, t-shirts and bare feet. A height gauge (Harpenden Stadiometer, Holtain Ltd., UK) with a precision of $\pm 1 \mathrm{~mm}$ was used for height measurements. Body weight and body mass index (BMI) were measured by bioelectric impedance analysis device (Tanita BC-418 MA Professional, Japan).

\subsection{Test Protocol}

The SenseWear Pro3 Armband (SWA) (BodyMedia Inc., Pittsburgh, PA, USA) device is a multi-sensor body monitor based on a model recognition approach for energy expenditure and physical activity prediction. During the intervention week, daily physical activity levels of the children were monitored using the SWA during the 24 hours for 6 days, without physical education lessons (Hinkley, O'Connell, \& Okely 2012; Trost, Pate, Freedson, Sallis, \& Taylor, 2000; Hislop et. al., 2014; Acebo et al., 1999; Taylor, Williams, Farmer, \& Taylor, 2015). The participants wore the SWA device over the triceps muscle of the dominant arm at the midpoint between the acromion and the olecranon. Children were instructed to wear SWA for 24 hours/6-day except for water-based activities (pre-test). With the help of SWA software (SWA software, version 7.0; BodyMedia Inc.), the participant features (gender, age, height, body weight, demographic information such as the cigarette use and the dominant hand) were uploaded from the computer to the device. After 6 consecutive days during 24 hours, the data on the removed device was transferred by using algorithms developed by the manufacturer back to the computer. In this study, total energy expenditure (TEE), physical activity level (MET), step (STEP), physical activity duration (PAD), lying-down duration (LD) and sleep duration (SD) values were taken with SWA. Throughout the intervention week, all participants were asked not to make any changes in their daily work and leisure routines. Participants knew that they were involved in a physical activity study while trying to avoid the potential Hawthorne effect and, they were monitored their activities. Beginning from the day immediately following the end of the audiovisual education program, the physical activity levels of the groups were re-determined in the same way (6 days) (post-test).

\subsection{Statistical Analysis}

Shapiro-Wilk test was used for the normality tests of all data. Since all of the data showed normal distribution $(p>0.05)$, parametric tests were performed. The variances between the groups were determined by one-way ANOVA, and in case of any difference between the groups, multiple comparison test was used in order to 
determine which group was the difference. The statistical calculations of the study were done with IBM SPSS 25.0 statistics program, and $\mathrm{P}<0.05$ level was accepted as significant in all tests.

\section{Results}

The audiovisual educational program was administered to EG and EGP in 6 consecutive days during 24 hours. TEE, MET, STEP, PAD, LD and SD values of the groups were taken before (pre-test) and after (post-test) the intervention week. In terms of baseline results, before the audiovisual educational program (pre-test), no significant difference was observed between the average metabolic values of the students. This situation showed a homogeneous distribution in our groups ( $p>0.05$, Table 2 ). After the audiovisual education programs (post-test), a significant increase was observed in the TEE, STEP and MET values of the groups ( $<<0.05$; Table 3 ). According to multiple comparison results when compared to the $\mathrm{CG}$, the TEE and MET values were significantly higher in favor of EGP $(p=0.030)$, and in step values were also significantly higher in favor of $E G(p=0.050)$ and $E G P(p=0.001)$ (Table 3). The results were presented between the Tables 1 and Table 3.

Table 1. Descriptive physical characteristics of the study group

\begin{tabular}{|c|c|c|c|c|c|}
\hline \multirow[b]{2}{*}{ Variables } & \multirow[b]{2}{*}{ Group } & \multirow[b]{2}{*}{$\mathrm{N}$} & \multirow[b]{2}{*}{$M(S D)$} & \multicolumn{2}{|c|}{$95 \% \mathrm{CI}$} \\
\hline & & & & LB & UB \\
\hline \multirow{4}{*}{ Height (cm) } & EG & 22 & $156.9(7.8)$ & 153.4 & 160.3 \\
\hline & EGP & 23 & $154.2(7.5)$ & 150.0 & 157.5 \\
\hline & $\mathrm{CG}$ & 21 & $158.1(9.2)$ & 153.9 & 162.3 \\
\hline & Total & 66 & $156.3(8.2)$ & 154.3 & 158.4 \\
\hline \multirow{4}{*}{ Weight (kg) } & EG & 22 & $44.3(7.5)$ & 41.0 & 47.6 \\
\hline & EGP & 23 & $43.0(7.7)$ & 39.7 & 46.3 \\
\hline & $\mathrm{CG}$ & 21 & $44.7(7.1)$ & 41.5 & 48.0 \\
\hline & Total & 66 & $44.0(7.4)$ & 42.2 & 45.8 \\
\hline \multirow{4}{*}{ BMI $\left(\mathrm{kg} / \mathrm{m}^{2}\right)$} & EG & 22 & $17.9(2.0)$ & 17.0 & 18.8 \\
\hline & EGP & 23 & $18.0(1.9)$ & 17.2 & 18.8 \\
\hline & $\mathrm{CG}$ & 21 & $17.5(1.7)$ & 16.7 & 18.2 \\
\hline & Total & 66 & $17.8(1.8)$ & 17.4 & 18.3 \\
\hline
\end{tabular}

Note. $\mathrm{CI}=$ confidence; $\mathrm{LB}=$ lower bound, $\mathrm{UB}=$ upper bound; $\mathrm{BMI}=$ body mass index; $\mathrm{EG}=$ educational group; $\mathrm{EGP}=$ educational group with parents; $\mathrm{CG}=$ control group. 
Table 2. Descriptive values of the study group's physical activity parameters

\begin{tabular}{|c|c|c|c|c|c|c|c|c|}
\hline \multirow[b]{3}{*}{ Variables } & \multirow[b]{3}{*}{ Group } & \multirow[b]{3}{*}{$\mathrm{N}$} & \multicolumn{3}{|c|}{ PRE-TEST } & \multicolumn{3}{|c|}{ POST-TEST } \\
\hline & & & \multicolumn{3}{|c|}{$95 \% \mathrm{CI}$} & \multirow[b]{2}{*}{$M(S D)$} & \multicolumn{2}{|c|}{$95 \% \mathrm{CI}$} \\
\hline & & & $M(S D)$ & LB & UB & & LB & UB \\
\hline \multirow{4}{*}{$\begin{array}{c}\text { TEE } \\
\left(\text { Kcal.day }^{-1}\right)\end{array}$} & EG & 22 & $1854.8(576.3)$ & 1599.3 & 2110.3 & $2081.2(582.6)$ & 1822.9 & 2339.5 \\
\hline & EGP & 23 & $1763.1(534.9)$ & 1531.8 & 1994.4 & $2126.5(509.8)$ & 1906.1 & 2347.0 \\
\hline & CG & 21 & $1656.2(365.4)$ & 1489.9 & 1822.6 & $1736.1(361.5)$ & 1571.5 & 1900.6 \\
\hline & Total & 66 & $1759.7(501.7)$ & 1636.3 & 1883.0 & $1987.2(517.8)$ & 1859.9 & 2114.5 \\
\hline \multirow{4}{*}{$\begin{array}{c}\text { STEP } \\
\left(\text { number.day }^{-1}\right)\end{array}$} & EG & 22 & $14230.9(2161.5)$ & 13272.5 & 15189.3 & $15907.0(2048.2)$ & 14998.9 & 16815.1 \\
\hline & EGP & 23 & $13790.5(2421.9)$ & 12743.2 & 14837.8 & $16803.9(2443.1)$ & 15747.4 & 17860.4 \\
\hline & CG & 21 & $13503.5(2408.2)$ & 12407.3 & 14599.7 & $14199.6(2471.7)$ & 13074.5 & 15324.7 \\
\hline & Total & 66 & $13846.0(2317.0)$ & 13276.4 & 14415.6 & $15676.3(2535.3)$ & 15053.0 & 16299.5 \\
\hline \multirow{4}{*}{ 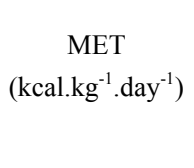 } & EG & 22 & $1.7(0.3)$ & 1.5 & 1.8 & $1.9(0.3)$ & 1.8 & 2.0 \\
\hline & EGP & 23 & $1.7(0.4)$ & 1.5 & 1.8 & $2.0(0.3)$ & 1.9 & 2.2 \\
\hline & $\mathrm{CG}$ & 21 & $1.6(0.5)$ & 1.4 & 1.8 & $1.7(0.5)$ & 1.5 & 1.9 \\
\hline & Total & 66 & $1.6(0.39)$ & 1.5 & 1.7 & $19(0.4)$ & 1.8 & 2.0 \\
\hline \multirow{4}{*}{$\begin{array}{c}\text { PAD } \\
\left(\text { min.day }^{-1}\right)\end{array}$} & EG & 22 & $206.1(69.0)$ & 175.5 & 236.7 & $233.1(63.6)$ & 204.9 & 261.3 \\
\hline & EGP & 23 & $215.0(71.3)$ & 184.2 & 245.9 & $253.9(77.9)$ & 220.2 & 287.5 \\
\hline & CG & 21 & $190.7(69.5)$ & 159.1 & 222.4 & $203.9(88.8)$ & 163.4 & 244.3 \\
\hline & Total & 66 & $204.3(69.7)$ & 187.2 & 221.5 & 231.1(78.8) & 211.7 & 250.4 \\
\hline \multirow{4}{*}{$\begin{array}{c}\text { LD } \\
\left(\text { min.day }^{-1}\right)\end{array}$} & EG & 22 & $498.1(62.8)$ & 470.3 & 526.0 & $514.7(63.1)$ & 486.7 & 542.7 \\
\hline & EGP & 23 & $517.4(53.0)$ & 494.5 & 540.3 & $482.2(51.7)$ & 459.9 & 504.6 \\
\hline & CG & 21 & $515.1(71.0)$ & 482.8 & 547.4 & $518.8(61.2)$ & 490.9 & 546.6 \\
\hline & Total & 66 & $510.2(62.1)$ & 495.0 & 525.5 & $504.7(60.2)$ & 489.9 & 519.5 \\
\hline \multirow{4}{*}{$\begin{array}{c}\text { SD } \\
\left(\text { min.day }^{-1}\right)\end{array}$} & EG & 22 & $394.3(44.1)$ & 374.7 & 413.8 & $425.1(65.7)$ & 396.0 & 454.3 \\
\hline & EGP & 23 & $380.5(76.3)$ & 347.5 & 413.5 & $443.3(111.9)$ & 394.9 & 491.7 \\
\hline & $\mathrm{CG}$ & 21 & $375.6(70.1)$ & 343.7 & 407.5 & $389.2(77.8)$ & 353.8 & 424.7 \\
\hline & Total & 66 & $383.6(64.6)$ & 367.7 & 399.4 & $420.0(89.5)$ & 398.0 & 442.0 \\
\hline
\end{tabular}

Note. ${ }^{*} p<0.05 ; \mathrm{CI}=$ confidence; $\mathrm{LB}=$ lower bound, $\mathrm{UB}=$ upper bound; $\mathrm{EG}=$ educational group; $\mathrm{EGP}=$ educational group with parents; $\mathrm{CG}=$ control group; $\mathrm{TEE}=$ total energy expenditure; $\mathrm{MET}=$ physical activity level; $\mathrm{PAD}=$ physical activity duration; $\mathrm{LD}=$ =lying-down duration; $\mathrm{SD}=$ sleep duration.

Table 3. ANOVA result between groups for physical activity parameters

\begin{tabular}{|c|c|c|c|c|c|c|c|c|}
\hline \multirow[b]{2}{*}{ Variable } & \multicolumn{4}{|c|}{ PRE-TEST } & \multicolumn{4}{|c|}{ POST-TEST } \\
\hline & $\mathrm{N}$ & $M(S D)$ & $\mathrm{F}$ & $p$ & $M(S D)$ & $\mathrm{F}$ & $p$ & Sig. Differ \\
\hline $\begin{array}{c}\text { TEE } \\
\left(\text { Kcal.day }^{-1}\right)\end{array}$ & 66 & $1759.7(501.7)$ & 0.84 & 0.44 & $1987.2(517.8)$ & 4.00 & $0.023 *$ & $\mathrm{EGP}>\mathrm{CG}$ \\
\hline $\begin{array}{c}\text { STEP } \\
\left(\text { number.day }^{-1}\right)\end{array}$ & 66 & $13846.0(2317.0)$ & 0.53 & 0.59 & $15676.3(2535.3)$ & 7.03 & $0.002 *$ & $\begin{array}{c}\mathrm{EG}>\mathrm{CG} \\
\mathrm{EGP}>\mathrm{CG}\end{array}$ \\
\hline 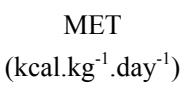 & 66 & $1.6(0.4)$ & 0.28 & 0.76 & $1.9(0.4)$ & 3.73 & $0.029 *$ & $\mathrm{EGP}>\mathrm{CG}$ \\
\hline $\begin{array}{c}\text { PAD } \\
\left(\min ^{\left.-d_{a y}{ }^{-1}\right)}\right.\end{array}$ & 66 & 204.3(69.6) & 0.67 & 0.51 & 231.1(78.4) & 2.31 & 0.107 & \\
\hline $\begin{array}{c}\text { LD } \\
\left(\text { min.day }^{-1}\right)\end{array}$ & 66 & $510.2(62.1)$ & 0.63 & 0.54 & $504.7(60.2)$ & 2.61 & 0.082 & \\
\hline $\begin{array}{c}\text { SD } \\
\left(\text { min.day }^{-1}\right)\end{array}$ & 66 & $383.6(64.6)$ & 0.48 & 0.62 & $420.0(89.5)$ & 2.13 & 0.128 & \\
\hline
\end{tabular}

Note. ${ }^{*} p<0.05$; $\mathrm{EG}=$ educational group; $\mathrm{EGP}=$ educational group with parents; $\mathrm{CG}=$ control group; $\mathrm{TEE}=$ total energy expenditure; MET=physical activity level; $\mathrm{PAD}=$ physical activity duration; $\mathrm{LD}=$ =lying-down duration; $\mathrm{SD}=$ sleep duration.

\section{Discussion}

In the current education system applied in schools, the importance and necessity of physical activity is generally given theoretically. In addition, many children are not sufficiently sensitivity and participation to physical 
activities that are many important, due to the lack of participation to the practices as a role model of educators and families together with the children. Therefore, this study, which was designed to increase the awareness level of students and families, aimed to examine the effect of visual-verbal education on the motivation of the family and the young people to be physically active. Thus, this study was investigated to determine how effective applied visual-verbal education and family members to create awareness in real physical activity behaviors on this behavior of children, and how young people were physically active.

In our study, the BMI rates of 66 boys, aged 13 years, were found to be $17.8 \pm 1.8 \mathrm{~kg} / \mathrm{m}^{2}$ and also the mean daily step counts measured by SWA, increased from $13846 \pm 2317$ steps/day to $15676.3 \pm 2535.3$ steps/day. Similar to our study, Raustorp, Pangrazi, and Stahle (2004) found the BMI rates of 47 boys, 13 years old, to be $19.7 \pm 3.1$ $\mathrm{kg} / \mathrm{m}^{2}$. They evaluated also physical activity levels with pedometer and found $16011 \pm 3960$ steps/day. According to the classification made by Tudor-Locke et al. (2004), based on the daily number of steps, it was observed that our group increased from "Silver" level to "Gold" level. Another study emphasized that interventions that teach children self-observation by using the pedometer were remarkable (Hustyi, Normand \& Larson, 2011). These studies were in line with our study and supported our results.

The development of extrinsic motivation programs designed to maximize participation in physical activity in children is potentially important (Frank, Flynn, Farnell, \& Barkley, 2018). Furthermore, according to Darden (1999), some of the benefits of visual educations in evaluation and teaching are; the student's motivation, interest and excitement may increase, helping to strive for learning, and can help to change the previously established negative behaviors in a positive way. Because, according to Bandura and Walters (1963), behaviors observed by children are depicted in children's minds, and then they are repeated almost exactly. For this reason, audiovisual training programs were applied to both EG and EGP, as intervention groups, to increase the intrinsic motivation for physical activity.

In our study, it was found out that the family plays an effective role in physical activity trends and can contribute directly by creating an environment that emphasizes exercise. In other words, we can say that parents can increase children's intrinsic motivation and can be effective in directing their physical activity. A study of Smolak, Levine, and Schermer (1999) has shown that the family was effective in increasing the tendency of their children to physical activity such as success in fatness, body dissatisfaction and weight loss.

In many studies have been reported that parents' efforts to increase their physical activity levels have a similar effect on children (Kang, Marshall, Barreira, \& Lee, 2009; Brown, Mummery, Eakin, \& Schofield, 2006; De Cocker, De Bourdeaudhuij, Brown, \& Cardon, 2007). Therefore, the STEP, TEE and MET values of the children resulted in the favor of EGP, as the family caused a similar effect of the children in our study to increase their orientation to physical activity (Table 3 ). The parent-child relationship depends mainly on the attitudes of the parents (Smolak, Levine, \& Schermer, 1999; Kang et al., 2009; Brown, Mummery, Eakin, \& Schofield, 2006; De Cocker et al., 2007).

Craig, Cameron, and Tudor-Locke (2013) reported that there was a measurable relationship between the daily steps of parents and children. Namely, with a 1000-step increase in the daily step count of a father, the boy also stated that the daily increase of 329-407 steps. Similarly, a 1000-step increase in the mother's daily step count showed that her son tended to take 263-439 extra steps a day. A father's or mother's daily increase of 3000 steps indicated that the activity level of the child could be correlated with a daily increase of 1.9-2.5 times. All these evaluations explain the increase in the number of daily STEPs in both of our intervention groups.

Recent reports have shown that sleep problems in children are becoming more common. For example, in a comprehensive study on Belgian children aged 6-13 years, reported that there were problems in initiating or maintaining sleep in one in three children (Spruyt, O'Brien, Cluydts, Verleye, \& FerriOdds, 2005). During childhood and adolescence, inadequate sleep, low academic performance (Dewald, Meijer, Oort, Kerkhof, \& Bögels, 2010), anxiety and depression (Gregory, Rijsdijk, Dahl, McGuffin \& Eley, 2006), obesity (Patel \& HuShort, 2008; Cappuccio, Taggart, \& Kandala, 2008) and have been associated with a series of health risk behaviors (McKnight-Eily et al., 2011). In our study, although there was no statistically significant difference in the SD of EG and EGP compared to CG, there was a significant increase in the SD (Table 3).

These increases in the physical activity levels of EG and EGP (e.g. TEE, STEP and MET) may have resulted from the increased effort of students during intervention periods. Therefore, it is important to increase physical activity levels in order to protect our children from the negative effects of insomnia.

\section{Conclusion}

The audiovisual education programs that used in our study concluded that children showed positive 
improvements in their physical activity levels. It was concluded that the extrinsic motivation elements which were used in audiovisual education programs contribute to increase physical activity levels by affecting the children's intrinsic motivations. In addition to this, it was concluded that increasing the awareness level of the families strengthened this education and contributed to more effective results. Also, it was concluded that the family played an effective role in physical activity trends and may contribute directly by creating an environment that emphasizes exercise. Therefore, it has been concluded that the family has increased the inner motivation of the child, and caused the negative behaviors to be positively changed. In addition, the creation of environments where children may exercise together with their peer groups as well as families may create a social interaction and contribute to their physical activity level. Finally, future studies should investigate the effects of programs in which children may work together with their peer groups.

\section{Acknowledgments}

We would like to special thanks the pedagogue, psychological counseling and guidance specialist, physical education teachers, all the students and their families for their contributions, time, efforts and decisive participations.

\section{References}

Acebo, C., Sadeh, A., Seifer, R., Tzischinsky, O., Wolfson, A. R., Hafer, A., \& Carskadon, M. A. (1999). Estimating sleep patterns with activity monitoring in children and adolescents: How many nights are necessary for reliable measures? Sleep, 22(1), 95-103. https://doi.org/10.1093/sleep/22.1.95

Aylaz, R., Gullu, E., \& Gunes, G. (2011). The Effect of Aerobic Walking Exercise on Depressive Symptoms. E-journal of DEUHYO, 4(4), 172-177. Retrieved from https://dspace.deu.edu.tr/xmlui/handle/12345/4600

Bandura, A., \& Walters, R. H. (1963). Social learning and personality development. Holt Rinehart and Winston: New York.

Branca, F., Nikogosian, H., \& Lobstein, T., (Eds.), (2007). WHO Europe. The determinants of obesity. The Challenge of Obesity in the WHO European Region and The Strategies For Response (pp. 13-23) Copenhagen.

Brown, W. J., Mummery, K., Eakin, E. G., \& Schofield, G. (2006). 10,000 steps Rockhampton: Evaluation of a whole community approach to improving population levels of physical activity. JPAH, 3(1), 1-14. https://doi.org/10.1123/jpah.3.1.1

Buyukkaragoz, S., \& Civi, C. (1998). General Teaching Methods (9th ed.). Self Education, Istanbul.

Cappuccio, F. P., Taggart, F. M., Kandala, N. B., Currie, A., Peile, E., Stranges, S., \& Miller, M. A. (2008). Meta-analysis of short sleep duration and obesity in children and adults. Sleep, 31(5), 619-626. https://doi.org/10.1093/sleep/31.5.619

Cordeiro, L. S., Lamstein, S., Mahmud, Z., \& Levinson, F. J. (2006). Adolescent malnutrition in developing countries: a close look at the problem and at two national experience. E-journal of Standing Committee on Nutrition, 31, 6-13. Retrieved from https://works.bepress.com/lorraine_cordeiro/3/

Craig, C. L., Cameron, C., \& Tudor-Locke, C. (2013). Relationship between parent and child pedometer-determined physical activity: a sub-study of the CANPLAY surveillance study. International Journal of Behavioral Nutrition and Physical Activity, 10, 1-8. https://doi.org/10.1186/1479-5868-10-8

Darden, F. G. (1999). Video Feedback for Student Learning and Performance: A Learning Stages Approach. Journal of Physical Education, Recreation and Dance, 70(9), 40-45. https://doi.org/10.1080/07303084.1999.10605967

De Cocker, K. A., De Bourdeaudhuij, I. M., Brown, W. J., \& Cardon, G. M. (2007). Effects of "10,000 steps Ghent": A whole-community intervention. Am $J$ Prev Med, 33(6), 455-463. https://doi.org/10.1016/j.amepre.2007.07.037

Der Ananian, C., \& Prohaska, T. R. (2007). Exercise and Physical Activity. In Encyclopedia of Gerontology (pp. 547-555). University of Illinois, Chicago, IL, USA. Retrieved from https://doi.org/10.1016/B0-12-370870-2/00069-X

Dewald, J. F., Meijer, A. M., Oort, F. J., Kerkhof, G. A., \& Bögels, S. M. (2010). The influence of sleep quality, sleep duration and sleepiness on school performance on children and adolescents: A meta-analytic review. Sleep Med Rev, 14(3), 179-189. https://doi.org/10.1016/j.smrv.2009.10.004

Donnelly, J. E., Blair, S. N., Jakicic, J. M., Manore, M. M., Rankin, J. W., \& Smith, B. K. (2009). American 
College of Sports Medicine. American College of Sports Medicine Position Stand. Appropriate physical activity intervention strategies for weight loss and prevention of weight regain for adults. Med Sci Sports Exerc, 41(2), 459-471. https://doi.org/10.1249/MSS.0b013e3181949333

Frank, M. L., Flynn, A., Farnell, G. S., \& Barkley, J. E. (2018). The differences in physical activity levels in preschool children during free play recess and structured play recess. Journal of Exercise Science \& Fitness, 16(1), 37-42. https://doi.org/10.1016/j.jesf.2018.03.001

Gentry, C. G. (1994). Introduction to Instrutional Development: Process and Tecnuques (Illustrated edition) Wadswort Pub. Co. California.

Graf, C., Beneke, R., Bloch, W., Bucksch, J., Dordel, S., Eiser S., \& Woll A. (2014). Recommendations for Promoting Physical Activity for Children and Adolescents in Germany. Obes Facts, 7, 178-190. https://doi.org/10.1159/000362485

Gregory, A. M., Rijsdijk, F. V., Dahl, R. E., McGuffin, P., \& Eley T. C. (2006). Associations between sleep problems, anxiety and depression in twins at 8 years of age. E-journal of Pediatrics, 118(3), 1124-1132. https://doi.org/10.1542/peds.2005-3118

Hinkley, T., O'Connell, E., Okely, A. D., Crawford, D., Hesketh, K., \& Salmon, J. (2012). Assessing volume of accelerometry data for reliability in preschool children. Med Sci Sports Exerc, 44(12), 2436-2441. https://doi.org/10.1249/MSS.0b013e3182661478

Hislop, J., Law, J., Rush, R., Grainger, A., Bulley, C., Reilly, J. J., \& Mercer, T. (2014). An investigation into the minimum accelerometry criteria for reliable estimates of habitual physical activity and definition of a standard measurement day in pre-school children. Physiol Measurment, 35(11), 2213-2228. https://doi.org/10.1088/0967-3334/35/11/2213

Hustyi, K. M., Normand, M. P., \& Larson, T. A. (2011). Behavioral assessment of physical activity in obese preschool children. Journal of Applied Behavior Analysis, 44(3), 635-639. https://doi.org/10.1901/jaba.2011.44-635.

Kang, M., Marshall, S. J., Barreira, T. V., \& Lee, J. O. (2009). Effect of pedometer-based physical activity interventions: A meta-analysis. Res $Q$ Exerc Sport, 80(3), 648-655. https://doi.org/10.1080/02701367.2009.10599604

Lester, P. M. (2000). Visual Communication: Images with Messages (2nd ed.). Wadsworth.

McKnight-Eily, L. R., Eaton, D. K., Lowry, R., Croft, J. B., Presley-Cantrell, L., \& Perry, G. S. (2011). Relationships between hours of sleep and health-risk behaviors in US adolescent students. Prev Med, 53(4-5), 271-273. https://doi.org/10.1016/j.ypmed.2011.06.020

Myles, S. F., Mary, A. L., Tim, S. A., Moonseong, H., \& Angelo, P. (2002). Weight Criticism During Physical Activity, Coping Skills, and Reported Physical Activity in Children. Pediatrics, 110(2). https://doi.org/10.1542/peds.110.2.e23

Patel, S. R., HuShort F. B. (2008). Sleep duration and weight gain: a systematic review. Obesity Silver Spring, 16(3), 643-653. https://doi.org/10.1038/oby.2007.118

Raustorp, A., Pangrazi, R. P., \& Stahle, A. (2004). Physical activity level and body mass index among schoolchildren in south-eastern Sweden. Acta Paediatr, 93(3), 400-404. https://doi.org/10.1111/j.1651-2227.2004.tb02969.x

Republic of Turkey Ministry of Health Public Health Agency of Turkey. (2014). Turkey Physical Activity Guide. Publication No: 940 (2nd ed., pp. 2-3), Ankara.

Smolak, L., Levine, M. P., \& Schermer, F. (1999). Parental input and weight concerns among elementary school $\begin{array}{llllll}\text { children. Int } J & \text { Eat 263-271. }\end{array}$ https://doi.org/10.1002/(SICI)1098-108X(199904)25:3<263::AID-EAT3>3.0.CO;2-V

Spruyt, K., O’Brien, L. M., Cluydts, R., Verleye, G. B., \& Ferri, R. (2005). Odds prevalence and predictors of sleep problems in school-age normal children. $J$ Sleep Res, 14(2), 163-176. https://doi.org/10.1111/j.1365-2869.2005.00458.x

T.C. Ministry of Health, Public Health Agency of Turkey. (2014). Turkey Physical Activity Guide. Publication No: 940 (2nd ed., pp. 2-3), Ankara.

Taylor, R. W., Williams, S. M., Farmer, V. L., \& Taylor, B. J. (2015). The stability of sleep patterns in children 3 
to 7 years of age. J Pediatr, 166(3), 697-702. https://doi.org/10.1016/j.jpeds.2014.11.014

The State of World Population. (2014). The Power of 1.8 Billion Adolescents, Youth And The Transformation of the Future (pp. 2-4). DC: The State of World Population.

Thompson, W. R., Gordon, N. F., \& Pescatello, L. S. (Eds.). (2009). American College of Sports Medicine. ACSM's Guidelines for Exercise Testing and Prescription (8th ed.). Lippincott Williams \& Wilkins, Philadelphia.

Trost, S. G., Pate, R. R., Freedson, P. S. Sallis, J. F., \& Taylor, W, C. (2000). Using objective physical activity measures with youth: how many days of monitoring are needed? E-journal of Med Sci Sports Exerc, 32(2), 426-431. Retrieved from http://citeseerx.ist.psu.edu/viewdoc/download?doi=10.1.1.476.1412\&rep=rep1\& type $=$ pdf

Tudor-Locke, C., Pangrazi, R. P., Corbin, C. B., Rutherford, W. J., Vincent, S. D., Raustorp, A., Tomson, L. M., \& Cuddihy, T. F. (2004). BMI-referenced standards for recommended pedometer-determined steps/day in children. Preventive Medicine, 38(6), 857-864. https://doi.org/10.1016/j.ypmed.2003.12.018

Turkey Statistical Institute. (2010). Address based population registration system results. Retrieved from http://report.tuik.gov.tr/ reports

World Health Organization, Regional Committee for Europe. (2015). Physical activity strategy for the WHO European Region. Vilnius, Lithuania, DC: World Health Organization.

\section{Copyrights}

Copyright for this article is retained by the author(s), with first publication rights granted to the journal.

This is an open-access article distributed under the terms and conditions of the Creative Commons Attribution license (http://creativecommons.org/licenses/by/4.0/). 